Revue des patrimoines

\title{
Les cultures équestres européennes : définitions, tectonique et implications patrimoniales
}

Jean-Pierre Digard

\section{OpenEdition}

Journals

Édition électronique

URL : http://journals.openedition.org/insitu/9655

DOI : 10.4000/insitu.9655

ISSN : 1630-7305

Éditeur

Ministère de la culture

Référence électronique

Jean-Pierre Digard, «Les cultures équestres européennes : définitions, tectonique et implications patrimoniales », In Situ [En ligne], 18 | 2012, mis en ligne le 31 juillet 2012, consulté le 20 avril 2019. URL : http://journals.openedition.org/insitu/9655 ; DOI : 10.4000/insitu.9655

Ce document a été généré automatiquement le 20 avril 2019



In Situ Revues des patrimoines est mis à disposition selon les termes de la licence Creative Commons Attribution - Pas d'Utilisation Commerciale - Pas de Modification 4.0 International. 


\title{
Les cultures équestres européennes : définitions, tectonique et implications patrimoniales
}

\author{
Jean-Pierre Digard
}

1 Bien que Saumur soit un lieu où il s'accomplit tous les jours des miracles, ce deuxième colloque sur «Le cheval et ses patrimoines » s'annonce d'emblée comme une entreprise difficile, et cela pour au moins deux raisons :

- tout d'abord, il nous faudra faire mieux ou (pour rester réaliste) aussi bien qu'à Tulle où s'est tenu, les 15,16 et 17 juin dernier, le premier colloque sur « Le cheval et ses patrimoines » - un colloque au contenu passionnant, à l'organisation impeccable et à l'ambiance à la fois studieuse et chaleureuse ;

- en outre, alors qu'à Tulle le but était d'explorer assez librement un large champ - « Le cheval et ses patrimoines » - pour étudier les moyens de favoriser l'identification, la connaissance, la conservation/restauration et la mise en valeur de ces patrimoines, nous devrons, à Saumur, passer du grand angle au zoom, mais au zoom sur un sujet malaisé à cadrer : sur « Les patrimoines de l'équitation française », c'est-à-dire sur ce qui concerne : a) l'utilisation du cheval sous la selle, à l'exclusion de celle du cheval de trait ;

b) l'équitation française, à l'exclusion de toute autre, si tant est que l'on sache exactement ce que c'est que l'équitation française...

2 L'inscription de l'« équitation de tradition française » au patrimoine culturel immatériel de l'humanité, dont nous nous réjouissons tous légitimement, ne résout nullement cette difficulté de cadrage. Il n'est donc pas superflu que nous nous y arrêtions quelques instants, au risque, pour moi, de paraître vouloir jouer les trouble-fête - mais j'assume : comme vous savez, les chercheurs du CNRS sont payés pour chercher des problèmes là où les gens normalement constitués n'en voient pas, et pour leur trouver des solutions, mais ça, c'est une autre histoire ! 


\section{Culture(s) équestre(s)}

\section{Qu'est-ce qu'une culture équestre?}

3 Telle est la première question à se poser. La notion de culture équestre doit être entendue comme l'utilisation d'un animal particulier par une catégorie sociale particulière à des fins particulières dans un contexte environnemental et culturel particulier. Ces liaisons répondent en partie à des contraintes incontournables : par exemple, ce sont des données climatiques et épidémiologiques qui expliquent que les grandes civilisations équestres se trouvent dans les régions froides ou tempérées, et non dans les régions tropicales ou de mousson ; mais il n'y a pas d'explication autre que culturelle ou de "style ethnique $»^{1}$ au fait que les Mongols et les Turcs d'Asie centrale ne montent que des hongres et les Iraniens que des étalons.

4 Ce questionnement peut-il être transposé aux équitations occidentales? Autrement dit: existe-t-il, en Europe, des styles équestres « ethniques » ou nationaux ? Il est courant, par exemple, d'opposer implicitement une équitation française, réputée "de légèreté », et une équitation allemande, disons plus directive. Mais quand on cherche à expliciter leurs différences, on s'aperçoit qu'il n'est pas si aisé de répondre à des questions telles que : qu'est-ce que l'« équitation de tradition française ", ou que la " tradition équestre française ", ou encore que l'« école française d'équitation »? Et quels en sont précisément les éléments constitutifs?

Plutôt que d'une équitation particulière, il s'agit d'une manière particulière de pratiquer l'équitation (une reprise de dressage imposée peut se comparer à une partition de musique: seule l'interprétation varie). La caractéristique principale de cette manière « française » réside dans une discrétion toute particulière des «aides " (mains, jambes, « assiette ») - cf. le fameux « souffle de la botte »-, d'où son qualificatif d'« équitation de légèreté ». En dépit de leur extrême discrétion, ces aides doivent néanmoins suffire pour obtenir " un cheval "calme, en avant, droit", mais aussi vibrant, flexible et équilibré " (selon les mots du général Durand) ${ }^{2}$, de manière à produire chez lui une tension - le « rassembler »-, des mouvements amples et brillants, et une décontraction de l'avantmain, signe d'une complète inhibition des résistances - le cheval « cède », il consent à sa propre domination. Petites causes, grands effets, dans le respect absolu du cheval : ainsi pourrait être brièvement résumé l'idéal de l'art équestre « à la française ».

Une dose supplémentaire de difficulté arrive avec les questions suivantes : cette manière d'équitation est-elle exclusivement française ? Qu'a-t-elle de spécifiquement français?

7 Rappelons que d'assez nombreux cavaliers, et non des moindres, comme Nuño Oliveira (au Portugal), le colonel Denis Bogros (au Maroc) ou Jean-Claude Racinet (aux États-Unis) ont pratiqué à haut niveau, enseigné et diffusé au-delà de nos frontières cette équitation de légèreté. À l'étranger, une institution comme l'École espagnole de Vienne s'en réclame également et légitimement.

8 Si cette manière équestre peut être qualifiée de « française ", n'est-ce pas simplement, et seulement, parce que c'est en France qu'elle est née (si l'on gomme ses racines italiennes), qu'elle s'est développée, qu'elle a été entretenue et perfectionnée de manière ininterrompue depuis Antoine de Pluvinel (1550-1620) jusqu'à nos jours, en une histoire qui fut construite par de grands innovateurs et de non moins grands 
« synthétiseurs » - François Robichon de La Guérinière (1688-1751), François Baucher (1796-1873), le capitaine Charles-Hubert Raabe (1811-1889), le général Alexis L'Hotte (1825-1904), le capitaine Étienne Beudant (1863-1949) pour ne citer que ceux-là -, en une histoire qui eut aussi pour ciment le travail quotidien et anonyme de milliers de cavaliers civils et militaires qui testèrent, appliquèrent et diffusèrent sur le terrain les principes élaborés par ces grands « maîtres de l'œuvre équestre » ${ }^{3}$.

En revanche, c'est en vain que l'on chercherait quelque lien que ce soit entre cette culture équestre française et une "identité nationale» française que, du reste, personne, y compris au défunt ministère du même nom, ne s'est montré capable de définir.

Bref, il y aurait tout intérêt à dépasser ces débats, équestres aussi bien que politiques, et, pour cela, à les transcrire en des termes plus neutres - surtout si l'on veut pouvoir comparer les équitations et/ou les cultures équestres entre elles. L'anthropologie de l'action développée par une cavalière, Carole Ferret, à partir d'une intuition géniale de l'ethno-linguiste André-Georges Haudricourt ${ }^{4}$, offre à cet égard une piste intéressante. La classification qu'elle fait des actions en quatre catégories - directes positives, indirectes positives, directes négatives et indirectes négatives - compatibles ou non avec certaines cultures, peut en effet fort bien s'appliquer à l'équitation: l'action directe positive est celle qui s'exerce sur le cheval forcé par des aides très interventionnistes à faire exclusivement ce que son cavalier veut qu'il fasse - cas correspondant grosso modo à une certaine équitation allemande -; l'action indirecte négative est celle qui s'exerce sur le cheval canalisé par des aides qui se contentent de l'empêcher de faire ce que son cavalier ne veut pas qu'il fasse - cas de l'équitation française que l'on ne saurait mieux illustrer qu'en citant Étienne Beudant qui résume ainsi l'apport de son livre Dressage du cheval de selle : « La conclusion est le principe absolu du cheval libre que d'Aure et Baucher ont posé en termes différents, mais de signification identique : "placer le cheval et le laisser faire de lui-même au lieu de vouloir l'y contraindre" (d'Aure) ; "qu'il croie qu'il est son maître et c'est alors qu'il est notre esclave" (Baucher). $\|^{5}$

\section{Il n'y a pas une mais des cultures équestres}

11 S'il y a une équitation française, c'est, corollairement, qu'il existe aussi une ou des équitation(s) qui ne sont pas française(s). Contrairement à une opinion répandue dans certains milieux équestres, il n'y a pas une mais des équitations ou, pour élargir le débat, des cultures équestres (voir mon amicale controverse avec le général Durand à la $\mathrm{XI}^{\mathrm{e}}$ Journée de la recherche équine à l'Institut national agronomique de Paris en mars 1985) ${ }^{6}$.

12 Même en Europe - surtout peut-être en Europe -, on peut aussi distinguer des cultures trait vs selle, trait de luxe (qui utilise des voitures de carrossiers) vs trait de travail (utilisant des véhicules de charrons, pour reprendre une distinction chère à Jean-Louis Libourel), équitation de travail ou sportive de haut niveau vs équitation de loisir (randonnée, tourisme), sports équestres vs hippisme, sports équestres eux-mêmes divisés en dressage, obstacle, endurance, hippisme lui-même divisé en trot vs galop, etc.

Pour compliquer encore les choses, plusieurs de ces cultures européennes se sont constituées à partir d'emprunts à d'autres cultures (courses de galop importées d'Angleterre au XVIII ${ }^{e}$ siècle), parfois extra-européennes (apports des équitations musulmanes à l'équitation académique à ses débuts et à la cavalerie légère militaire au début du XIXe siècle, trot enlevé emprunté par les Britanniques aux cavaliers de polo de leur empire des Indes puis diffusé en Europe à partir de l'Angleterre, etc.). De même, 
certaines équitations européennes sont à l'origine d'équitations extra-européennes (équitations espagnole et portugaise importées en Amérique au XVI ${ }^{e}$ siècle en même temps que le cheval lui-même) ${ }^{7}$.

Plusieurs types de traits interviennent dans la différenciation des cultures équestres : les types ou races de chevaux utilisés, leurs usages, les modes de débourrage et de dressage, les techniques et les matériels de monte, l'équipement des cavaliers, etc. De plus, tous ces traits n'interviennent pas au même titre, fournissant, selon les cas, des indicateurs, «traits objectifs de différenciation que révèle une étude substantiviste et contrastive des faits ", ou des marqueurs, «traits reconnus et retenus par les usagers comme symboles d'identité et d'altérité », ou encore des stéréotypes, " jugements de valeur, transmis par la tradition, portés sur l'en - et l'hors - groupe ». Ou, en d'autres termes, d'usage plus courant: des traits distinctifs, les uns à " usage interne ", pour se reconnaitre entre soi, les autres à " usage externe », qui permettent aux autres de vous identifier, ou de vous railler car, comme on sait, les cavaliers ont les uns envers les autres la critique facile.

\section{Les cultures équestres ne sont pas immuables}

Le changement des cultures équestres n'est pas propre à notre époque moderne ; elles ont toujours changé - «Rien n'est immortel, ni la nature, ni l'homme, écrivait Arthur Schopenhauer, le seul élément permanent, c'est le changement ». Mais il est vrai que le changement va en s'accélérant, en équitation comme ailleurs.

Alors qu'il s'est écoulé plus de deux millénaires entre la domestication du cheval et sa première utilisation (pour l'attelage), puis encore deux millénaires avant de parvenir à des techniques de monte efficaces, capables de fonder des cavaleries militaires, nous sommes passés, en Europe, en moins de deux cents ans, d'une équitation privilège nobiliaire d'Ancien régime, où le roi faisait l'admiration de ses courtisans parce qu'il crevait sous lui plusieurs chevaux au cours d'une seule et même chasse ${ }^{8}$, à une équitation notabiliaire incarnée par la figure de l'«homme de cheval», à la fois professionnel, polyvalent et « respectueux » (c'est-à-dire « économe ») du cheval.

Cette évolution n'a pas été linéaire. Elle a été à diverses reprises, répétons-le, ponctuée, bousculée, enrichie, selon les cas, par des courants et des influences venues d'ailleurs, principalement par le vecteur des équitations orientales via le sud de la Méditerranée (Maghreb et Espagne musulmane) et l'Europe (Turquie ottomane, Balkans...) au moment des guerres d'Italie, puis de nouveau à l'occasion des campagnes napoléoniennes.

Aujourd'hui, l'heure du déclin a-t-elle sonné ? Depuis que le cheval a quitté la sphère de l'utilitaire pour celle du loisir, la culture de l'« homme de cheval» s'efface peu à peu devant une nouvelle culture équestre correspondant à une population de "nouveaux cavaliers » (dont $80 \%$ de cavalières), culture à la fois :

- baroque (aux pratiques de plus en plus diversifiées, empruntées à des horizons culturels variés : horse-ball inspiré du pato argentin, équitation « western » américaine, doma vaquera espagnole...),

- hédoniste (axée sur la recherche de plaisir et de sociabilité plus que sur l'effort sportif)

- et sentimentale (en entrant dans la sphère des loisirs, le cheval a accédé à un nouveau statut culturel, intermédiaire entre celui des animaux de rente, dont il ne fait plus partie, et celui des animaux de compagnie, qu'il tend à rejoindre). 
D'où l'émergence d'une double tendance quelque peu paradoxale : celle d'un engouement croissant pour le cheval dans sa diversité, mais aussi pour un cheval mal connu, idéalisé, métamorphosé en une sorte de "cheval Barbie ", avec un fossé qui se creuse de plus en plus entre une minorité de professionnels de l'équitation et une majorité qui réclame toujours plus de cheval mais de moins en moins d'équitation?.

Tous ces mouvements, déplacements dans l'espace et/ou recouvrements dans le temps, relèvent d'une tectonique des cultures qui peut se comparer à la tectonique des plaques des géophysiciens. Dans cet enchevêtrement de plaques, où se trouve le patrimoine et quel patrimoine?

\section{Implications patrimoniales}

\section{L'immatériel et le matériel}

21 Une première difficulté surgit immédiatement avec l'expression même de « Patrimoine culturel immatériel », que l'UNESCO définit ainsi :

"On entend par "patrimoine culturel immatériel" les pratiques, représentations, expressions, connaissances et savoir-faire - ainsi que les instruments, objets, artefacts et espaces culturels qui leur sont associés - que les communautés, les groupes et, le cas échéant, les individus reconnaissent comme faisant partie de leur patrimoine culturel. Ce patrimoine culturel immatériel, transmis de génération en génération, est recréé en permanence par les communautés et groupes en fonction de leur milieu, de leur interaction avec la nature et de leur histoire, et leur procure un sentiment d'identité et de continuité, contribuant ainsi à promouvoir le respect de la diversité culturelle et la créativité humaine ${ }^{10}$.»

En dépit des précautions de vocabulaire déployées dans cette définition, l'expression de « patrimoine culturel immatériel » suggère - et c'est là que réside sa principale difficulté une coupure ou une distinction entre une partie de la culture qui serait «immatérielle » et une autre qui ne serait que "matérielle ». L'idée d'un tel découpage ne date pas d'hier; elle s'incarne en particulier dans la catégorie «culture matérielle » qui servait autrefois, en ethnologie, à désigner l'ensemble des techniques par lesquelles les hommes assurent leur alimentation, leur protection, etc. Cette appellation perdure chez certains archéologues, anglo-saxons notamment, tenants des material culture studies, qui ne disposent, pour étudier les populations et sociétés du passé, que des seuls vestiges matériels livrés par les fouilles. C'est pourtant l'un d'eux, le grand préhistorien français (et, soit dit en passant, homme de cheval) André Leroi-Gourhan (1912-1986) qui a, le premier, appelé à se méfier de cette notion, précisément parce qu'il est impossible de séparer les objets et les outils, des connaissances, des savoir-faire, des gestes et des chaînes opératoires sans lesquels les premiers ne sauraient être conçus et mis en action ${ }^{11}$. Les langues elles-mêmes, dont l'usage ne nécessite pas d'outils et dont l'immatérialité ne paraît guère faire de doute à première vue, sont en fait inséparables de leurs locuteurs et des réalités qu'elles servent à décrire.

Avec l'équitation, nous nous trouvons face à un ensemble composite associant :

1) Tout ce qui est nécessaire à l'élevage des chevaux, à leur logement et à leur entretien (haras, écuries, granges et greniers, forge et ferrure, etc.), les lieux (selleries, carrières, hippodromes, manèges, paddocks, pistes) et les équipements (harnachements) que 
requièrent leur monte et leur dressage - nous sommes bien là dans la patrimoine «matériel ».

2) Un vaste corpus de connaissances (hippologiques, éthologiques, etc.), de compétences et de savoir-faire, par nature "immatériels ", car, comme presque toujours en matière d'utilisation d'animaux, les pratiques équestres font davantage appel à des manières de faire qu'à des outils matériels (voix plus que fouet, aides naturelles plus que cravache ou éperons, etc.); de plus, les innombrables "querelles d'écuyers", qui animent en permanence le microcosme équestre, selon la part d'influence que chacun reconnait à tel ou tel maître, montrent la part prépondérante que revêt, dans les apprentissages équestres, la transmission directe, orale ou par imitation, « immatérielle » en tout cas, de maître à élève ${ }^{12}$, des savoirs, savoir-faire et sensibilités équestres - une part en tout cas bien plus importante que celle assurée par les écrits, «matériels ", car, bien qu'il existât une remarquable profusion des traités d'équitation et d'hippologie ${ }^{13}$, le général L'Hotte a justement souligné qu'en matière équestre, « les livres n'apprennent qu'à ceux qui savent déjà ".

3) et enfin, les chevaux eux-mêmes, qui constituent à la fois :

a) Un patrimoine vivant, biologique, notamment génétique, qui n'est pas pour autant un " patrimoine naturel » (intitulé impropre de notre séance de jeudi après-midi), mais bien, au contraire, un patrimoine éminemment culturel car longuement cultivé, sélectionné par l'homme à des fins particulières. (Soit dit en passant, cet aspect de la question n'est pas sans rapport avec la conservation de la biodiversité domestique : en effet, alors que les écoles de Jerez, de Lisbonne et de Vienne n'utilisent que des chevaux espagnols, lusitaniens et lipizzans, les écuyers du Cadre noir ne sont pas les cavaliers d'une seule race équine ; certaines races de chevaux utilisées au Cadre noir ne sont plus sélectionnées sur les critères qui les rendaient autrefois particulièrement aptes à la pratique de cette équitation: certaines races, comme le selle français sont désormais presque exclusivement orientées vers le concours de saut d'obstacles, tandis que d'autres, comme l'anglo-arabe, sont en déclin démographique).

b) Les chevaux représentent également un "matériel pédagogique ", pourrait-on dire, car, une fois dressés, comme l'a excellemment montré Patrice Franchet d'Espèrey, ils participent à leur tour à la formation des élèves-écuyers ; ainsi, les écuyers sont porteurs de connaissances sur le cheval, et les chevaux d'une partie des connaissances des écuyers ; la culture équestre constitue donc un patrimoine qui s'incarne dans du vivant et dont la sauvegarde s'avère d'autant plus délicate qu'elle suppose d'en confier une partie à des animaux vivants sous la forme de comportements qu'il faut sans cesse entretenir par un travail régulier.

Il est important de bien mesurer et intérioriser cette extrême diversité des patrimoines du cheval car, vous l'aurez compris, son corollaire est une variété égale des méthodes particulières de collecte, d'archivage et de valorisation de ces patrimoines.

\section{Fossilisation vs " mercatisation » (variante du terme " marketing » pour désigner la clientélisation des acteurs culturels) ${ }^{14}$}

31 Face à l'embarras suscité par un patrimoine diffus coincé dans l'enchevêtrement de ces plaques culturelles évoquées plus haut, il faut bien sûr essayer de dégager une définition socle du patrimoine équestre, caractérisée au minimum par une certaine permanence, 
une faculté à "faire tendance", non pas au sens actuel de "mode», mais à celui d'inscription dans une durée couvrant plusieurs générations.

Le flou qui subsiste quant à cette question doit inciter à une attitude de sauvegarde, en vertu du "principe de précaution » suivant: l'équitation n'est en effet pas à l'abri des modes (comme celle, aujourd'hui, de l'équitation soi-disant " éthologique » ${ }^{15}$ ), modes qui peuvent conduire à l'abandon de telle ou telle pratique ou technique; le propre des modes étant d'être éphémères, il est plus prudent et toujours plus simple de veiller à sauvegarder ce que l'on possède, que d'avoir à recréer, le cas échéant, ce que l'on aurait laissé disparaître. Ni la «fabrique du patrimoine ${ }^{16}$, ni les 《relances de traditions ${ }^{17}$ ne vont de soi !

Mais il y a plus: entretenir la tradition ne suffit pas, il faut aussi l'enrichir, d'où une nécessaire activité de recherche : recherche intellectuelle qui peut se manifester par des colloques, des publications; recherche en technique équestre par le travail régulier des écuyers et des chevaux; recherche de convergences entre l'art équestre et d'autres formes d'expression esthétique comme la musique, la danse, les arts plastiques, etc.

Face à l'émergence décrite précédemment d'une double tendance paradoxale, à la fois d'engouement croissant pour le cheval dans sa diversité, mais aussi pour un cheval mal connu, idéalisé, métamorphosé en une sorte de "cheval Barbie ", l'attitude à adopter, notamment en matière d'offre culturelle, doit elle aussi être double : il faut, d'une part, prendre acte de cet engouement et l'encourager, notamment dans sa dimension d'ouverture au vaste monde ; mais il faut aussi, d'autre part, se garder de toute tentation de "surfer ", dans un but de "marketing ", sur ces éléments de « culture Barbie » qui ne peuvent que nuire, à la longue, aux cavalier(e)s comme au cheval lui-même (cf. la mode, arrivée d'outre-Atlantique, comme tant d'autres calamités, du «cheval miniature » que l'IFCE s'apprête, hélas, à reconnaître ${ }^{18}$ et qui serait bien inspiré de méditer, pendant qu'il est encore temps, l'expérience de la filière cunicole ruinée par l'introduction du lapin nain dans les familles comme animal de compagnie ${ }^{19}$...).

Enfin, la conservation des patrimoines équestres apparait d'autant plus délicate qu'elle est contestée par certains, ouvertement ou en catimini, au nom de l'économie de la filière équine ; face à cette alternative, la question qui se pose est la suivante : au simple vu de la croissance du marché du cheval en France (parti de quelques dizaines de milliers après la guerre, le nombre de cavaliers réguliers ou occasionnels aurait aujourd'hui atteint le million, cavalières à $80 \%{ }^{20}$, doit-on se précipiter dans le courant du marketing, au risque de commettre des erreurs irréparables, comme de laisser disparaître des savoirs techniques ancestraux d'élevage et d'utilisation du cheval (aujourd'hui, la race «selle français » tend à éliminer les autres et, dans les centres équestres devenus établissements commerciaux, où "le client est roi », $70 \%$ des cavaliers pratiquant la compétition ne s'intéressent qu'au $\mathrm{CSO})^{21}$, ou bien doit-on au contraire résister à cette pression soi-disant pragmatique, au risque, cette fois, de sembler réactualiser l'étiquette élitiste et passéiste qui a longtemps été accolée au monde du cheval ? Particulièrement en matière équestre, la marge de manœuvre patrimoniale est donc étroite entre, d'une part, l'attachement inconditionnel à un passé idéalisé mais révolu et, d'autre part, le bradage inconsidéré de ce passé au nom du changement pour le changement.

Pour éviter de conclure sur un ton pessimiste qui serait déplacé en ce jour de célébration de l'équitation de tradition française, je voudrais dire que ces difficultés présentent au moins cet avantage : n'en déplaise aux beaux esprits qui ont tendance à considérer le 
cheval comme une préoccupation insignifiante ou obsolète, les enjeux intellectuels et sociétaux soulevés par cet animal et ses patrimoines, loin de se limiter au pré carré d'un trivial quadrupède, recoupent au contraire des choix de société fondamentaux.

\section{NOTES}

1. - LEROI-GOURHAN, André. Le Geste et la parole, technique et langage. Paris : Albin Michel, 1964, t. II, p. 89-94 ; LEVI-STRAUSS, Claude. La Voie des masques. Paris : Agora, 1988 (1979), p. 123-125.

2. - DURAND, Général Pierre. L'Équitation française. Arles : Actes Sud, 2008, p. 47.

3. - MONTEILHET, André. Les Maîtres de l'œuvre équestre. Paris : Le Livre de Paris/Odège, 1979.

4. - FERRET, Carole. "Techniques iakoutes aux confins de la civilisation altaïque du cheval. Contribution à une anthropologie de l'action ", thèse de doctorat. Paris : EHESS, 2006 ; FERRET, Carole. Une Civilisation du cheval. Les usages de l'équidé de la steppe à la taïga. Paris: Belin, 2009; FERRET, Carole. "Vers une anthropologie de l'action ». Dans L'Homme, n²02, avril-juin 2012, p. 113-140 ; HAUDRICOURT, André-Georges. «Domestication des animaux, culture des plantes et traitement d'autrui ». Dans L'Homme, vol. II, n 1, 1962, p. 40-50.

5. - BEUDANT, Étienne. Dressage du cheval de selle. Paris : Berger-Levrault, 1943, p. 6.

6. - Le Cheval dans la société: du steak à l'œuvre d'art. Synthèse de la table ronde du 6 mars 1985, XI Journée de la recherche équine. Paris : Institut national agronomique, 1985.

7. - DIGARD, Jean-Pierre. Une Histoire du cheval. Art, techniques, société. Arles: Actes Sud, 2004, passim.

8. - SALVADORI, Philippe. "Chasse, équitation et représentations du roi aux XVII ${ }^{\mathrm{e}}$ et XVIII siècles ». Dans ROCHE, Daniel et REYTIER, Daniel (eds.). Les Écuries royales du XVI ${ }^{e}$ au XVIII ${ }^{e}$ siècle. Paris : Association pour l'Académie d'art équestre de Versailles/Établissement public du musée et du domaine de Versailles, 1998, p. 111-117.

9. - DIGARD, Jean-Pierre. « Du travail au plaisir, du respect à la compassion : fonctions, statuts et cultures du cheval de selle dans la France du XXe siècle ». Dans ROCHE, Daniel et REYTIER, Daniel (eds.). À cheval ! Écuyers, amazones et cavaliers. Paris : Association pour l'Académie d'art équestre de Versailles, 2007, p. 243-265.

10. - Article 2 de la Convention pour la sauvegarde du patrimoine culturel immatériel, UNESCO, 17 octobre 2003.

11. - LEROI-GOURHAN, André. Le Geste et la parole, technique et langage. Paris : Albin Michel, 1964, passim.

12. - Voir notamment FRANCHET D'ESPEREY, Patrice. La Main du maître. Réflexions sur l'héritage équestre. Paris : Odile Jacob, 2007.

13. - MENNESSIER DE LA LANCE, Général. Essai de bibliographie hippique. Paris : Librairie Lucien Dorbon, 1915-1921, 2 vol. ; rééd. : Nieuwkoop, B. de Graaf, 1971.

14. - LAMARCHE, Thomas. "Service public : nouvelle rationalité des acteurs ou nouveau marché ?». Études de Communication, n²3, 2001 [en ligne, consulté le 10 janvier 2010].

15. - Comme si toute équitation n'était pas forcément fondée sur une connaissance approfondie du comportement des chevaux! 
16. - HEINICH, Nathalie. La Fabrique du patrimoine. De la cathédrale à la petite cuillère. Paris : Éditions de la Maison des Sciences de l'Homme, 2009.

17. - BROMBERGER, Christian et CHEVALLIER, Denis (eds.). Carrières d'objets. Innovations et relances. Paris : Éditions de la Maison des Sciences de l'Homme/Mission du Patrimoine Ethnologique, 1999. 18. - ROZO, Sylvie. "Réglementation: la reconnaissance du cheval miniature en marche». Équ'Idée, $\mathrm{n}^{\circ} 76$, automne 2011, p. 7.

19. - « Le plus grand prédateur du lapin est le lapin nain », me confiait il y a quelques années le président de la Société française de cuniculture.

20. - Sur ces évolutions et leurs dangers, voir TOURRE-MALEN, Catherine. «Évolution des activités équestres et changement social en France à partir des années 1960 ». Le Mouvement Social (Éd. La Découverte), $n^{\circ} 229$, octobre-décembre 2009, p. 41-59.

21. - Annuaire écus 2011. Le Pin au Haras, IFCE, 2011, p. 5 et 45.

\section{AUTEUR}

\section{JEAN-PIERRE DIGARD}

directeur de recherche émérite au CNRS, Paris digard@ivry.cnrs.fr 